\title{
PRODUCCIÓN DE HARINA DE FRIJOLES (PHASEOLUS VULGARIS) Y EVALUACIÓN SENSORIAL
}

\section{RED BEANS FLOUR'S PRODUCTION (PHASEOLUS VULGARIS) AND SENSORIAL ANALYSIS}

\author{
Ethel Indira Hernández García ${ }^{1}$ \\ Wendell Adrián Blandón Rivera ${ }^{1}$ \\ Rosmery Escorcia Rivera ${ }^{1}$ \\ Sandra Lorena Blandón Navarro ${ }^{2 *}$
}

(recibido/received: 16-Agosto-2017; aceptado/accepted: 29-Noviembre-2017)

\begin{abstract}
RESUMEN: El presente estudio tuvo como finalidad la obtención y caracterización de harina de frijol rojo (Phaseolus vulgaris) y evaluar su uso potencial en la elaboración de tortas dulces. Por lo tanto, experimentos de obtención de harina fueron realizados, y determinado el rendimiento del proceso. La harina de frijol fue utilizada en la formulación de torta a la que se le realizó los respectivos análisis sensoriales. Fue determinado que el tiempo de cocción es influenciado por el periodo de remojo, de modo que un remojo de los granos por un periodo de 6 horas reduce el tiempo de cocción en un 42 \% en comparación a aquellos granos que son sometidos a cocción sin remojo previo. La harina de frijoles presentó un diámetro promedio de las partículas de 0.191 $\pm 0.006 \mathrm{~mm}$. Este producto fue evaluado positivamente en cuanto al color y olor. En relación a la textura de la torta dulce, 70 \% de los panelistas colocan el producto en la escala de "me gusta" y "me gusta mucho". A partir de estos resultados es posible sugerir que la producción de harina de frijoles es técnicamente viable y que las operaciones de acondicionamiento de los granos favorecen la reducción del tiempo de cocción y consecuente ahorro energético.
\end{abstract}

PALABRAS CLAVE: Proteína vegetal; propiedades funcionales; grano rojo; cocción

\footnotetext{
1 Estudiante de cuarto año de ingeniería Agroindustrial. Universidad Nacional de Ingeniería. Recinto Augusto C. Sandino (UNI RUACS), Estelí, Nicaragua

2 Profesora titular, Universidad Nacional de Ingeniería, Recinto Augusto C. Sandino (UNI RUACS), Estelí, Nicaragua. *Autora para correspondencia, email: sandra.blandon@norte.uni.edu.ni
} 


\begin{abstract}
The aim of this study was to obtain and characterize red bean flour (Phaseolus vulgaris) and evaluate its potential use in the production of sweet cakes. Therefore, experiments to obtain flour were carried out, and the yield of the process was determined. The product obtained was used in the cake formulation, and sensory analysis was performed. It was determined that the cooking time is influenced by the soaking period, so that soaking of the grains for a period of 6 hours reduces the cooking time by $42 \%$ compared to those grains that are subjected to cooking without soaking previous. The red bean flour had an average particle diameter of $0.191 \pm 0.006$ $\mathrm{mm}$. This product was positively evaluated in terms of color and odor. In relation to the texture of the sweet cake, $70 \%$ of the panelists evaluated the product on the scale of "I like" and "I like it very much". From these results it is possible to suggest that the production of red bean flour is technically viable and the conditioning operations of the grains favor the reduction of the cooking time and consequent energy saving.
\end{abstract}

KEYWORDS: vegetal protein; functional properties; red grain; cooking

\title{
INTRODUCCIÓN
}

Las leguminosas de granos se han reconocido como una fuente importante de proteínas en la dieta de las poblaciones de muchas regiones del mundo. De acuerdo a la cantidad de consumo, las leguminosas pueden cubrir la necesidad humana de ingesta de proteína, pero además pueden proveer la calidad proteica deseada para la alimentación de grupos de poblaciones vulnerables (Garcia, 2003).

El frijol es una rica fuente de proteínas e hidratos de carbono, además de ser una buena fuente de vitaminas del complejo $\mathrm{B}$ como la niacina, rivoflavina, ácido fólico y la tiamina. Igualmente proporciona hierro, cobre, zinc, magnesio, calcio y tiene un gran contenido en fibra. También es una excelente fuente de ácidos grasos polinsaturados.

Los frijoles son fuentes adecuadas de aminoácidos esenciales isoleusina, leusina, fenilalanina, treonina y valina, En particular, presentan alto contenido en lisina, un aminoácido esencial y muy escaso en los cereales (Maldonado, 2005).

El siguiente trabajo tiene como finalidad el presentar una opción para el uso y consumo de frijoles, planteando métodos para disminuir el tiempo de cocción y presentando un producto elaborado a partir de la harina de frijoles, el cual fue analizado sensorialmente 


\section{MATERIALES Y MÉTODOS}

Fue utilizado frijol rojo (Phaseolus vulgaris) como materia prima para la producción de harina. El producto presentó $5 \%$ de impurezas, por lo tanto fueron realizadas las siguientes operaciones de procesamiento.

Primeramente, fue realizado el pesaje del frijol en balanza analítica de precisión $0.1 \mathrm{~g}$ (Ohaus Scout Pro SP601, capacidad 600 g). Después fue realizada la separación del frijol de los terrones, virutas y hojas. A seguir se seleccionaron para eliminar los que presentaban daños por insectos o por hongos. Los frijoles escogidos fueron lavados para eliminar la tierra o polvo adherido y así asegurar la inocuidad del producto. Posteriormente, solamente la mitad de estos fueron dejados en agua por 6 horas, a fin de comparar el efecto del remojo sobre la cocción de frijol.

La capacidad de absorción de agua (CAA) de los frijoles durante el remojo fue calculada a través de la siguiente ecuación, propuesta por (Mederos, 2006):

$$
\boldsymbol{C A A}=\frac{\text { Peso de la muestra despues de remojo }- \text { peso inicial de la muestra }}{\text { peso inicial de la muestra }} \times 100
$$

Se procedió a calentar agua hasta alcanzar los $94^{\circ} \mathrm{C}$, alcanzada esta temperatura se agregaron los frijoles con remojo y sin remojo por separado, con $6200 \mathrm{~mL}$ de agua al frijol sin remojo y 3400 $\mathrm{mL}$ al frijol con remojo previo. Concluido el periodo de cocción, los frijoles fueron escurridos para determinar el volumen de agua no retenida y utilizarla en la siguiente etapa. Los frijoles se dejaron enfriar para luego molerlos en una licuadora (marca Oster), durante la molienda se agregaron $1000 \mathrm{~mL}$ de agua al frijol sin remojo y $600 \mathrm{~mL}$ al frijol remojado. Los productos triturados se extendieron en moldes con un espesor de $2 \mathrm{~cm}$, se dejaron secar en horno de precisión compacto (Thermo Fisher Scientific, modelo PR305225G) a una temperatura de $75^{\circ} \mathrm{C}$ por 7 horas para ambas muestras. Luego del secado se hizo una segunda molienda en seco en la licuadora (marca Oster). La harina ya molida se pasó por un juego de tamices ASTM desde el número 30 hasta el 100 para análisis granulométrico.

Para la determinación del diámetro promedio de las partículas fue utilizada la ecuación:

$$
\mathrm{Dp}=\frac{1}{\sum_{i=1}^{n} \frac{x_{i}}{d p_{i}}} \quad \text { Ec. } 2
$$

Donde $x_{i}$ es la fracción másica de partículas de diámetro dp $\mathrm{p}_{\mathrm{i}}$.

Para hacer el análisis sensorial de la harina de frijol se realizó una torta con los siguientes ingredientes, como observados en la Tabla 1. 
Tabla 1. Ingredientes utilizados en la producción de torta de harina de frijoles

\begin{tabular}{c|c}
\hline Ingredientes & Dosificación \\
\hline Harina de frijol & $85 \mathrm{~g}$ \\
\hline Harina de avena & $85 \mathrm{~g}$ \\
\hline Polvo de hornear & $10 \mathrm{~g}$ \\
\hline Leche & $300 \mathrm{~mL}$ \\
\hline Canela & $3 \mathrm{~g}$ \\
\hline Huevo & 3 \\
\hline Azúcar & $20 \mathrm{~g}$ \\
\hline Margarina & $45 \mathrm{~g}$ \\
\hline Chocolate & $25 \mathrm{~g}$ \\
\hline
\end{tabular}

Se mezclaron todos los ingredientes, luego la mezcla se colocó en un molde rectangular y se procedió a hornearlo a $45^{\circ} \mathrm{C}$ durante 20 minutos, se enfrió y sirvió al panel para su degustación.

Para evaluar la torta a base de harina de frijol elaborada, se realizó un análisis sensorial en el laboratorio de agroindustria de la Universidad Nacional de Ingeniería, utilizando la metodología orientada al producto con diez panelistas no entrenados ya que este método proporciona la información sobre los gustos, aversiones, preferencias y requisitos de aceptabilidad, además son menos sensibles a las pequeñas diferencias del producto en evaluación con relación a productos similares.

\section{RESULTADOS Y DISCUSIÓN}

Una vez realizada la fase experimental, fue determinado que la capacidad de absorción de agua de los frijoles después del remojo fue de $81 \%$. El tiempo de cocción de los frijoles logró disminuirse en un $42 \%$ con el remojo, considerando que permanecieron con agua durante 6 horas y de acuerdo a la literatura el tiempo puede llegar hasta las 24 horas.

El diámetro promedio de las partículas de la harina de frijoles fue de $0.191 \pm 0.006 \mathrm{~mm}$ y no fueron observadas diferencias estadísticas significativas en el tamaño de las partículas de la harina obtenida a partir de frijoles remojados y no remojados.

En relación al análisis sensorial, el color del producto es una característica muy importante en los alimentos, ya que atrae la atención de los consumidores. Njintang, Mbofung y Waldron (2001) sugieren que la utilización de harinas como ingredientes para el procesamiento de alimentos depende de sus propiedades funcionales, por lo que la evaluación de cualidades sensoriales permite la determinación del grado de aceptabilidad de dichos productos por parte de los consumidores. Como se puede apreciar en la figura 1 este producto tiene alta aceptabilidad en cuanto a color dado que los encuestados ubican al producto entre la escala de "me gusta" y "me gusta mucho". 
Figura 1: Evaluación del color de la harina de frijoles

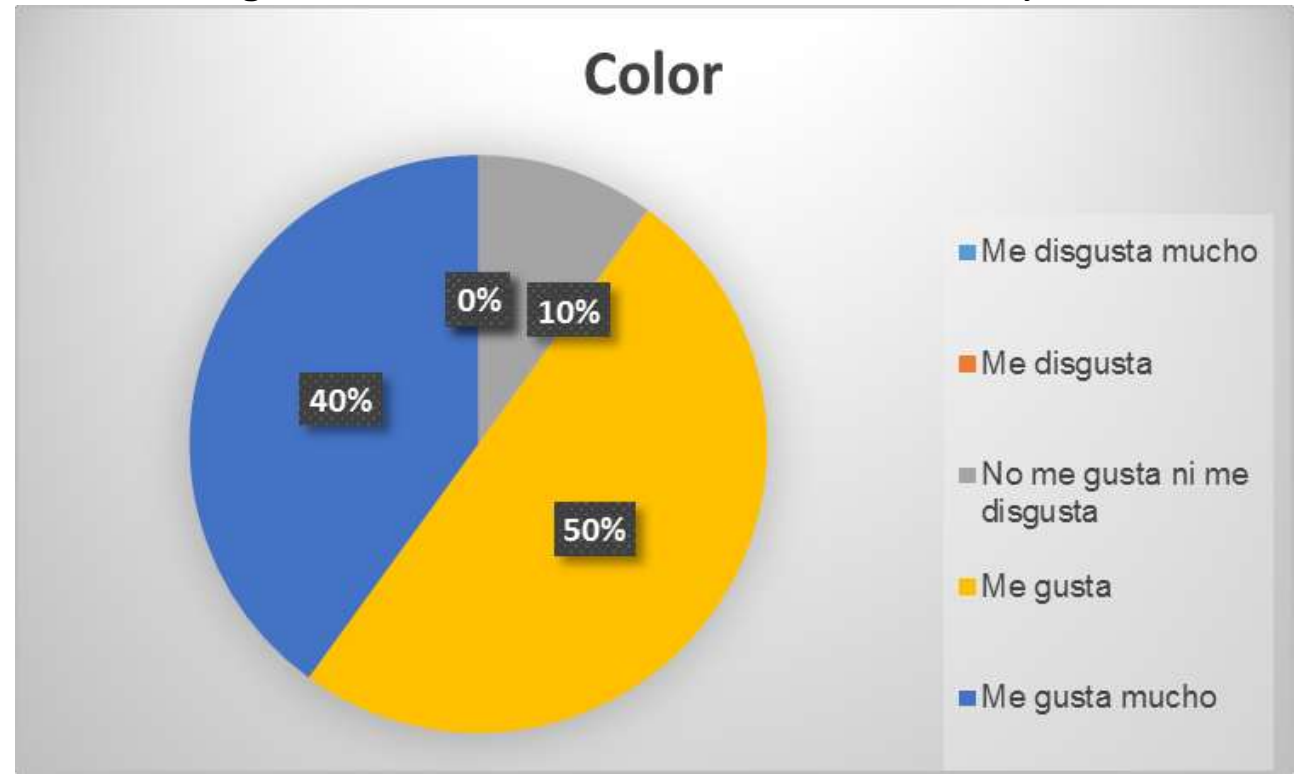

Fuente: Elaboración propia

El Olor del producto, obtuvo resultados similares al del color, de modo que los panelistas lo calificaron entre "me gusta" y "me gusta mucho" el olor del producto en un $100 \%$. Con respecto al sabor también se obtuvieron resultados satisfactorios.

La textura del producto recibió un $70 \%$ de aceptabilidad, el $30 \%$ restante de los encuestados se posicionó en la escala de "no me gusta, ni me disgusta", lo que indica una oportunidad de mejora en cuanto a la textura.

Figura 2: Evaluación de la textura del producto

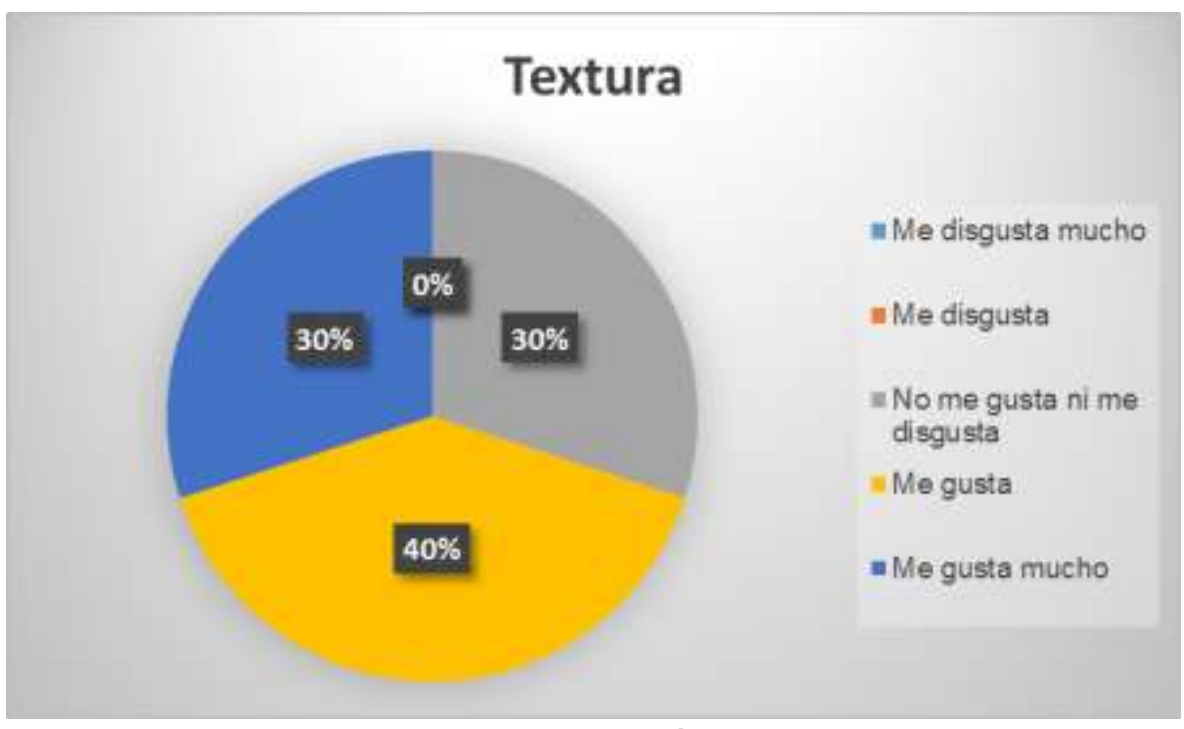

Fuente: Elaboración propia 


\section{CONCLUSIONES}

Los resultados de los experimentos sugieren que la producción de harina de frijoles rojos es técnicamente viable, de modo que la materia prima presenta características idóneas para la producción de harina dado que presenta un alto contenido de almidón por lo que su rendimiento es alto (mayor de $80 \%$ ).

El proceso de remojo de los frijoles, influye en el color del producto final, tornando más pálida a la harina obtenida de los frijoles que pasaron por remojo previo.

La harina con un $13 \%$ de humedad y con un tamaño promedio de partículas de $0.191 \pm 0.006$ $\mathrm{mm}$, puede ser utilizada en la formulación de tortas, sustituyendo parcialmente la harina de trigo.

\section{REFERENCIAS}

García, C. M. (1999). Una propuesta para la producción local de semilla de calidad por pequeños agricultores (No. IICA-PRIAG F03 1). San José, Costa Rica: IICA.

Maldonado, F. O. (2005). Aprovechamiento e industrialización del frijol (Phaseolus vulgaris). Recuperado el 23 de septiembre de 2017, de Cofupro: Disponible en: http://www.cofupro.org.mx

Mederos, Y. (2006). Indicadores de la calidad en el grano de frijol (Phaseolus vulgaris L.). Cultivos Tropicales, 27(3), 55-62.

Njintang, N., Mbofung, C., \& Waldron, K. W. (2001). In vitro protein digestibility and physicochemical properties of dry red bean (Phaseolus vulgaris) flour: Effect of processing

\section{SEMBLANZA DE LOS AUTORES}

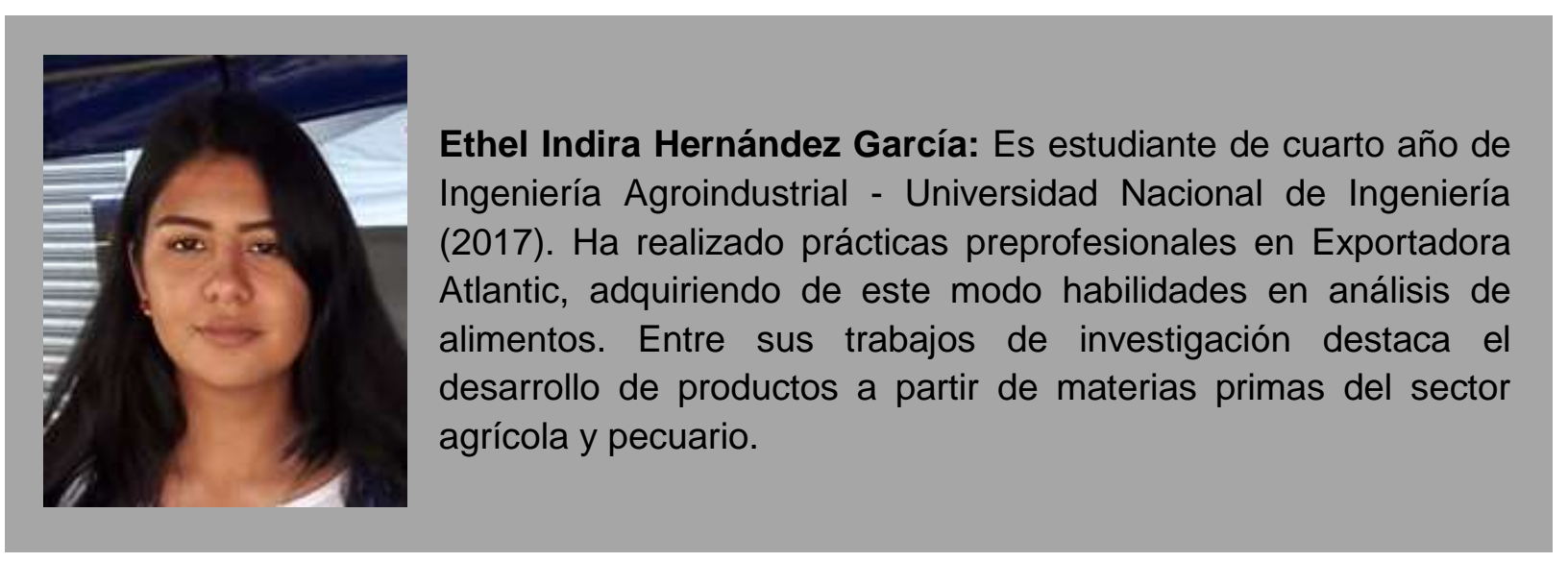



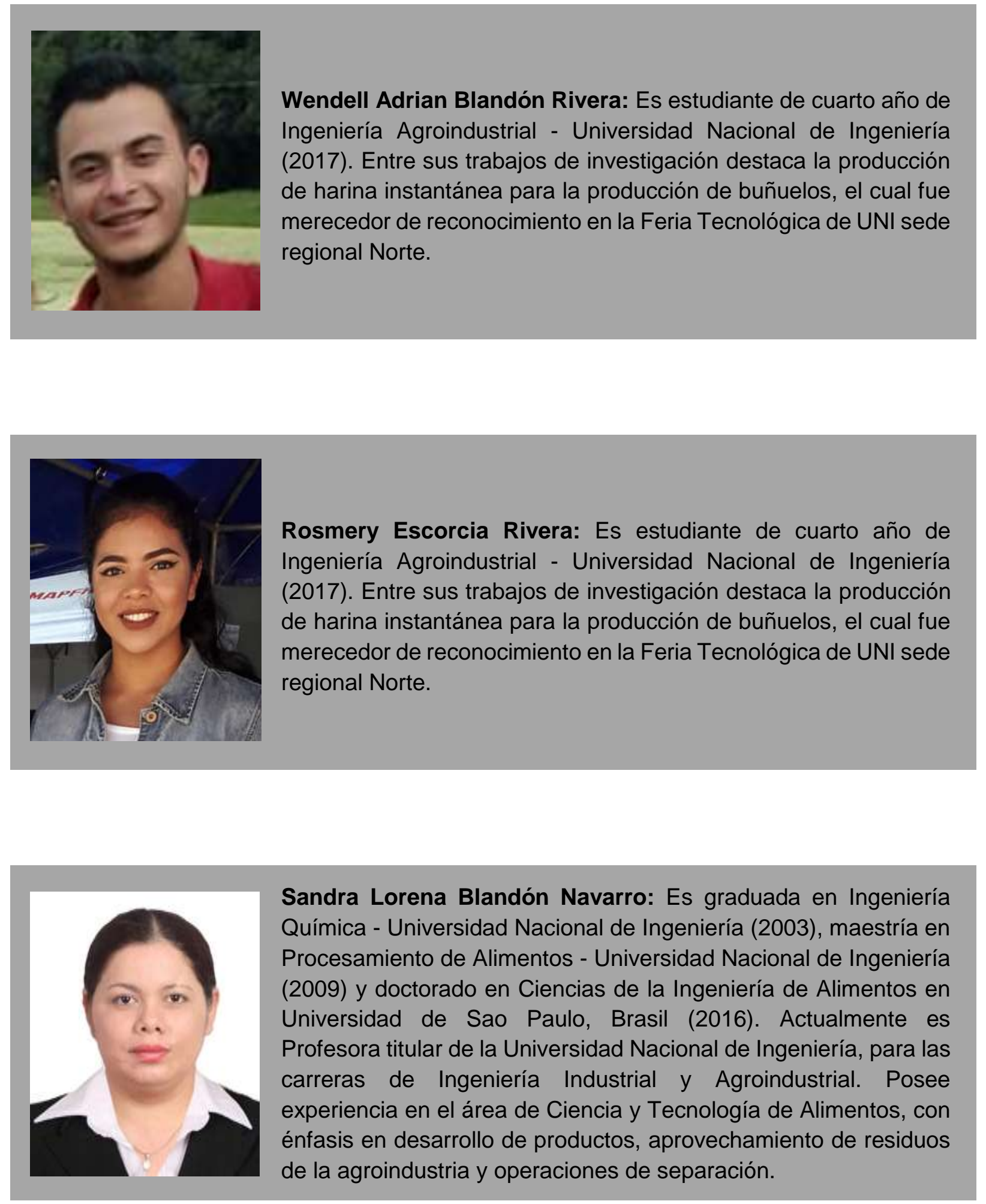